\title{
Relationship between urban construction and land subsidence in Beijing region
}

\author{
Q. Yang ${ }^{\mathrm{a}}, \mathrm{Y} . \mathrm{Ke}^{\mathrm{a}}$ \\ ${ }^{a}$ Beijing Key Laboratory of Resource Environment and Geographic Information System, Capital Normal \\ University, Beijing 100048, China \\ Email:yqins@.cnu.edu.cn
}

\begin{abstract}
Beijing is the capital of China with a population of about 21,729 million people, inhabiting an area of about 1,641 million square kilometers. Beijing has suffered land subsidence since 1935 and gradually formed five large land subsidence areas. With rapidly development of urban area, the constructions of multistorey and high-rise buildings could accelerate land subsidence, and the uneven land subsidence could also affect building stability. Persistent Scatterer for Interferometric SAR technique (PS- InSAR) was used to obtain time-series surface displacement information of Beijing urban area based on more than 50 scenes of TerraSAR$\mathrm{X}$ images during the periods of 2010-2016. In different hydrogeological background, large quantity of districts has been selected according to the age of building construction, the building load and building density. Standard deviation function has been used to detect uneven settlement blocks. We analyzed the relationship between land subsidence and urban construction from regional scale to local scale-using PS-InSAR and Geographic Information System (GIS) techniques. Results show that ground movements in Beijing is ranging from about $-141 \mathrm{~mm} / \mathrm{yr}$ (sinking) to $19 \mathrm{~mm} / \mathrm{yr}$ (uplift), and two subsidence funnel area mainly distributed in the east of Chaoyang district and gradually connected into a trip. The comparative analysis results indicate that the subsidence of the funnel area is still controlled by the compressible layer thickness at a depth $60-80 \mathrm{~m}$ and the changes of groundwater level at regional scale, and not completely relevant with the age of the building construction. In different hydrogeological background we found that some serious settlement areas appear in villages with high building density, the built age of these buildings relatively long and its subsidence rate gradually decreased from the center to the surrounding with settlement rate more than $100 \mathrm{~mm} / \mathrm{y}$. At local scale, 28 uneven settlement area has been discovered in subsidence funnel area. There are only two districts that the uneven subsidence shows relevant to building load, accounting for $7 \%$ of the overall uneven settlement area. The generation of uneven settlement blocks is still subject to the control of the water and the compressible layer thickness, and nothing to do with building age, building density and building load.
\end{abstract}

Keywords: $\quad$ Land subsidence, urban construction, building load, building age 
Yang et al., Study on the Relation between Urban Construction and Land Subsidence

\section{INTRODUCTION}

Land subsidence is an environmental geological phenomenon consisting in the slow surface elevation decrease under the effects of natural process and anthropogenic activities. Specifically, in urban areas, uneven settlements seriously cause damages to urban infrastructures and lead huge losses of national economy. Therefore, the continuous monitoring of land subsidence is critical for deeply understanding regional and local ground subsidence mechanism and providing remediation and contrasting measures as well as updated reference for urban construction.

Over the last two decades, a number of Interferometric Synthetic Aperture Radar (InSAR) techniques have been developed to monitor land deformation with high accuracy and high resolution also at large scales (Hooper et al., 2012). Among all, the Persistent Scatterer Interferometric SAR technique (PS-InSAR) has been set up to decrease the spatial-temporal decorrelation and atmospheric disturbance affecting the first InSAR applications .PS-InSAR focus on persistent scatterer(PS) points with high coherence and allows to retrieve long time series deformation for each PT (Ferretti et al., 2000, Ferretti et al., 2001,Tosi et al., 2016).

Beijing, the capital of China, has suffered land subsidence since 1935, the rate and extent of land subsidence showing an increasing trend. Mapping results produced by Small Baseline Subset (SBAS) approach reveals that Beijing plain has gradually formed five subsidence centers (Gao et al., 2015), and Beijing plain has experienced significant ground subsidence from 2010-2015 with maximum annual land subsidence rate of $146 \mathrm{~mm} / \mathrm{y}$ (Zhou et al., 2017).Studies reveals that the influence of fault zones is the geological cause of the formation of ground subsidence in Beijing (Gong et al., 2009, Chen et al., 2016). And the development of land subsidence is closely related to the changes of the second confined aquifer, although the land subsidence bowl is not perfect well with groundwater depression funnel (Zhu et al., 2015, Lei et al., 2016, Chen et al., 2017). Moreover, the places with the highest clay layer thickness did not overlap with the largest settlement, it majorly occurred in the cohesive soil thickness of 50-70m area (Lei et al., 2014, Zhu at al., 2014, Chen et al., 2016). Recently, large quantity of research focus on the relation between urban expansion and land subsidence development. Several investigations found that urbanization is an accelerating factor for subsidence process, land subsidence is significant when the region with high construction density and high building load (Yan et al., 2002, Jie et al., 2007, Hasanuddin et al., 2011, Chen et al., 2015) and the stress superposition effect that caused by large-scale buildings is remarkable on ground deformation (Tang et al., 2010, Cui et al., 2010). Further studies discovered that the subsidence rates have direct correlation with the age of building construction (Stramondo et al., 2008, Solari et al., 2016). But there's few research focus on the relation between uneven settlement and building construction.

In this work, PS-InSAR technique has been used to investigate the land subsidence spatial and temporal evolution trend in Beijing region. Specifically, this paper aims to discern whether the building construction is a factor that accelerates land subsidence process, and carries out the following aspects:

- PS-InSAR technique was used to obtain time-series surface displacement information of Beijing urban area based on more than 50 scenes of TerraSAR-X images during the periods of 2010-2016. The deformation results are evaluated and validated using the existing leveling surveys and GPS survey measurements.

- We divide the different hydrogeological backgrounds into six category according to the groundwater level and compressible thickness. And select lots of construction area in the settlement funnel area to discuss the pattern regular and influencing factor of the building settlement under different hydrogeological conditions at overall scale.

- Calculating the standard deviation of the building districts to discern uneven settlement district. And examining the feature of uneven settlement and doing thorough analysis considering the building density, the building load and the age of building, to explore the correlation between uneven settlement and building construction at local-scale.

\section{STUDY AREA}

The city of Beijing has a population of about 21,729 million people in 2016, with an area of 16,410 square kilometers, of which 6,200 square kilometers are the plain. Beijing is centered at the coordinates of about north latitude $39.54^{\circ}$ and east longitude $116.25^{\circ}$ and located on the northern part of the North China Plain (Error! Reference source not found.). It is bounded by Taihang Mountains to the western, by Jundu Mountains to northern and north-eastern and by alluvial-pluvial plains to southeastern formed by the combination of five 
Yang et al., Study on the Relation between Urban Construction and Land Subsidence

rivers: Yongding, Juma, Wenyu, Chaobai and Jiyun. The area is affected by a monsoon-influenced semi-arid and semi-humid continental climate. Beijing is one of the most water shortage cities in the world, two-thirds of urban water supply comes from groundwater extraction. (Chen et al. 2016).

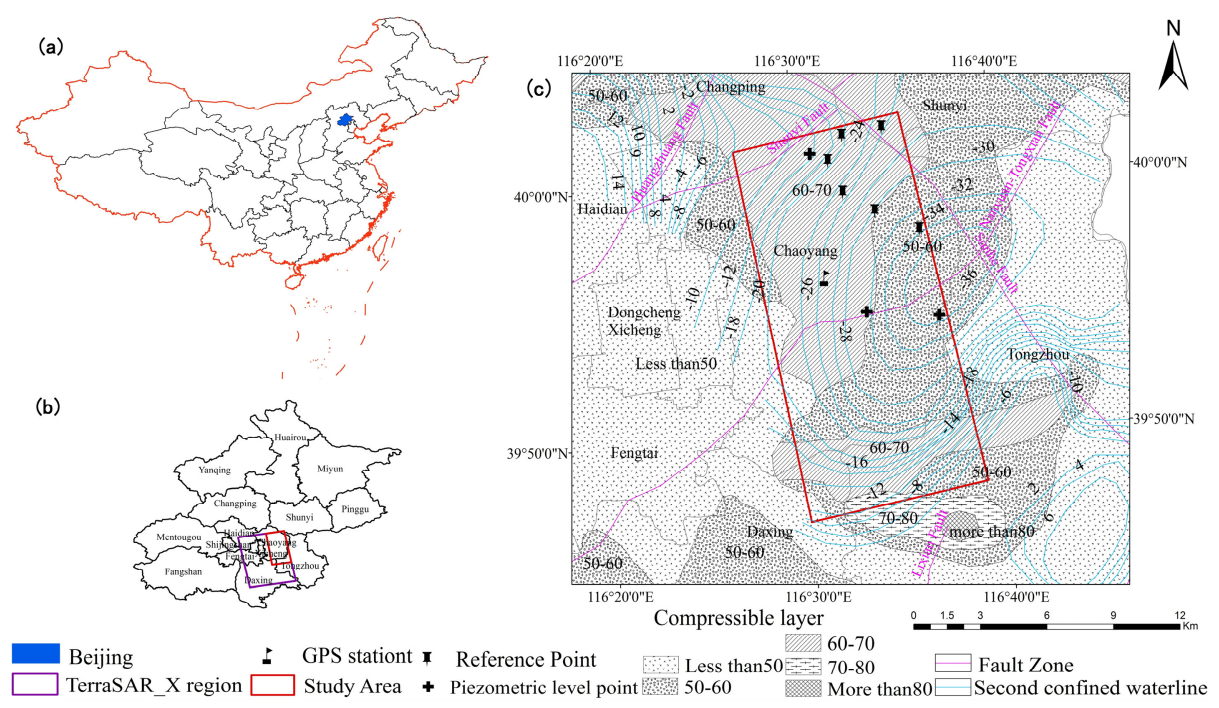

Figure 1. Location of (a) Beijing, China and (b) Study area. (c) Sketch of the Hydrogeological background

\section{METHOD}

\subsection{PS-InSAR products}

PS-InSAR technique focus on PSpoint that can be natural or man-made and have stable radiometric characteristics during long-series interval, to derive spatial-temporal evolution regular of ground deformation. PS-InSAR can overcome the shortcomings of the spatial-temporal decorrelation and atmospheric disturbance that InSAR produced.

The main steps of PS-InSAR monitoring method include (Figure 2): SAR image registration, differential interference processing with external DEM data, PS candidate points selection, subsidence information extraction using filter method and function model and verification.

For subsidence detection in the Beijing plain, more than 50 scenes of TerraSAR-X images during the periods of 2010-2016 has been used; these data were obtained from AIRBUS. The reliability of these interferometric data have successfully been proven by existing leveling surveys and GPS survey measurements.

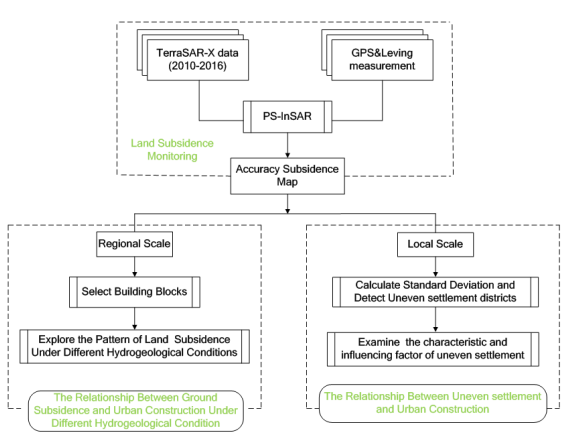

Figure 2. Flow chart of method

\subsection{Explore the regular of building district subsidence under different conditions at regional scale}

We divide the different hydrogeological backgrounds into six hydrogeological category according to the groundwater level and compressible thickness (Figure 3). Taking street blocks as a unit and avoiding groundwater and compressible layer junction place, we select 164 building blocks that thoroughly cover the entire settlement funnel area to prepare for a better study of the relationship between urbanization and settlement.

\subsection{The relation between uneven settlement and urban construction at local scale}

\subsubsection{Calculating standard deviation and detect uneven settlement district}

We calculate the standard deviation $(\sigma)$ of the building blocks to discern uneven settlement blocks through 
the formula (1) where $\mathrm{N}$ is the total number of points in the block, $x_{i}$ is the settlement rate of each point, $\mathcal{u}_{\text {is }}$ the average subsidence velocity in the block,. According to the foundation of the building deformation allowable value (foundation engineering project, 2004), we select the building blocks that the standard deviation is greater than 5 as uneven settlement blocks.

$$
\sigma=\sqrt{\frac{1}{N} \sum_{i=1}^{N}\left(x_{i}-u\right)^{2}}
$$

\subsubsection{Examine the characteristic and influencing factor of uneven settlement}

In order to explore the feature and factor of uneven settlement, we analyze the heterogeneity of subsiding blocks in different hydrogeological background. Firstly, we divided building districts into six different categories (Figure 3) according to the building age, building density, building load and building height. Secondly, the distribution characteristics of building district under different hydrogeological category have been analyzed by statistic means to assess the relation between urban construction and land subsidence.

\section{ANALYSIS AND DISCUSSION}

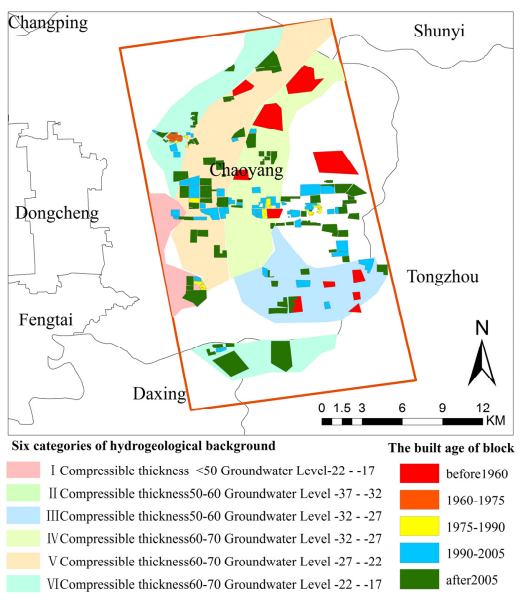

Figure 3. The age of blocks in six hydrogeological background

\subsection{Ground subsidence monitoring by PS-InSAR}

There are 1, 099, 639 million high coherent points extracted in Beijing plain within a total area of around $139,556 \mathrm{~km}^{2}$. The results demonstrate that the settlement rate is small in downtown, the north of Daxing and the west of Tongzhou. We found two obvious subsidence bowls that distributed over the east of Chaoyang District and gradually connected into a trip (Figure 4(a). To evaluate the quality of the InSAR results from TerraSAR-X, we select five level monitoring points compared with the nearest PS point.Results show that TerraSAR-X data are in good agreement with level measurement. Moreover, the average settlement rate error is $-14.6 \mathrm{~mm} / \mathrm{yr}$, the standard error is $6.0 \mathrm{~mm} / \mathrm{yr}$, indicating that the reliability of TERRASAR-X data (Figure $4(\mathrm{~b}))$.
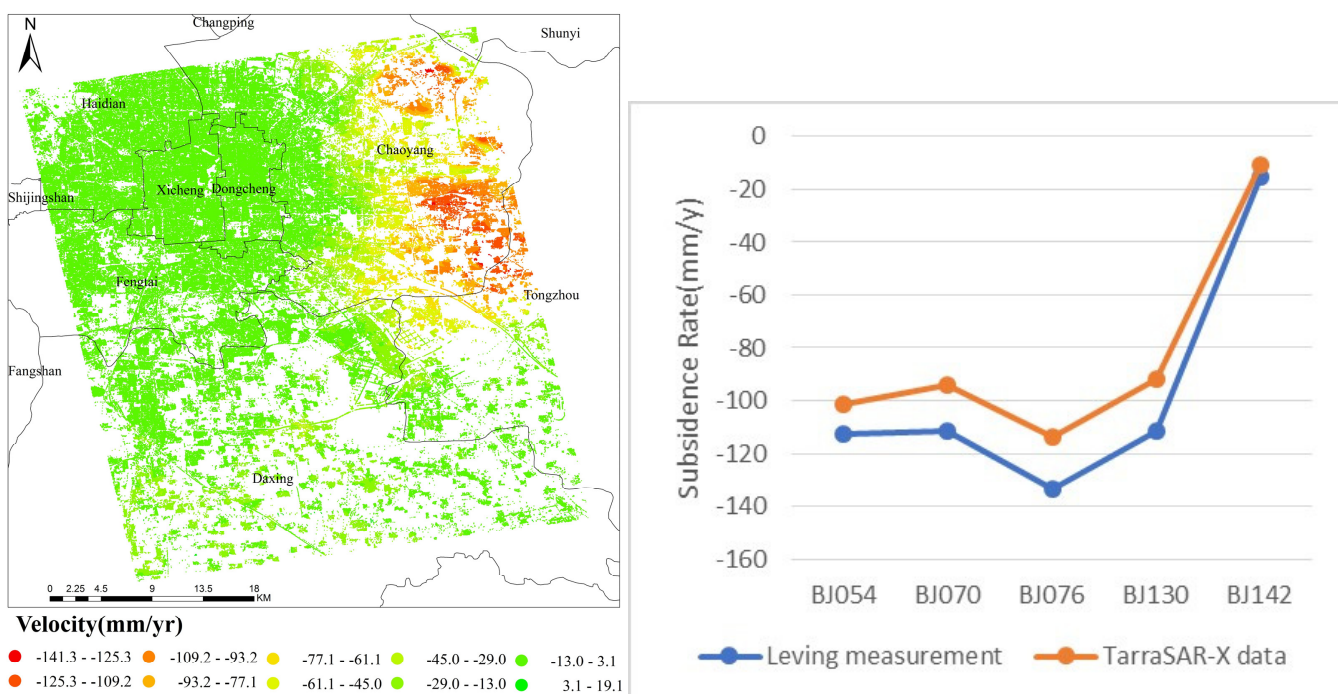

Figure 4. (a) Subsidence rate derived from TerraSAR-X (2010-2016) in Beijing plain (b) Comparison of TerraSAR-X data and leveling measurement 
Yang et al., Study on the Relation between Urban Construction and Land Subsidence

\subsection{Land subsidence characteristic under different hydrogeological category at regional scale}

The statistical analysis results indicate that the ground subsidence in subsidence bowls is mostly controlled by groundwater and compressible layers (Table 1), and not completely relevant with the age of the building construction (Figure 3). The subsidence occurs mainly in areas where the thickness of compressible layer is 50-70 $\mathrm{m}$, and average subsidence rate of the compressible layer in 50-60 m thickness is greater than the compressible layer thickness of $60-70 \mathrm{~m}$. Moreover, the ground subsidence rate also decreased with the change of groundwater level when the compressible layer thickness at $60-70 \mathrm{~m}$. We found that most of the serious settlement appear in building-intensive village, such as Heiqiao, Jinzhan, Dongba, Kouzi, Dongxu, Magezhuang, Dingxinzhuang, Dongxiaying and Wanziying. These villages were built relatively long and the subsidence rate gradually decreased from the center to the surrounding with settlement rate more than 100 $\mathrm{mm} / \mathrm{yr}$ (Figure5). This may be related to the groundwater changes of underground wells that privately excavate by villager.

Table 1. Distribution of PS subsidence rates in different geological backgrounds

\begin{tabular}{|c|c|c|c|c|c|c|}
\hline \multirow{2}{*}{$\begin{array}{c}\text { Compressible Layer Thickness(m) } \\
\text { Groundwater Level(m) }\end{array}$} & \multirow{2}{*}{$\begin{array}{c}<50 \\
-22--17\end{array}$} & \multicolumn{2}{|c|}{$50-60$} & \multicolumn{3}{|c|}{$60-70$} \\
\hline & & $-37--32$ & $-32--27$ & $-32--27$ & $-27--22$ & $-22--17$ \\
\hline PS point number & 16994 & 33454 & 19696 & 31431 & 39810 & 30075 \\
\hline Maximum Subsidence Rate(mm/yr) & -52.9 & -135.9 & -140.5 & -118.6 & -141.3 & -106.8 \\
\hline Minimum Subsidence Rate(mm/yr) & -7.9 & -19.5 & -47.1 & -19.8 & -6.7 & -4.6 \\
\hline Mean Subsidence Rate(mm/yr) & -23.1 & -91.7 & -94.4 & -67.9 & -40.6 & -41.8 \\
\hline Standard Deviation(mm/yr) & 12.2 & 22.7 & 15.8 & 21.4 & 23.3 & 22.1 \\
\hline
\end{tabular}

\subsection{The relationship between uneven settlement and urban construction at local scale}

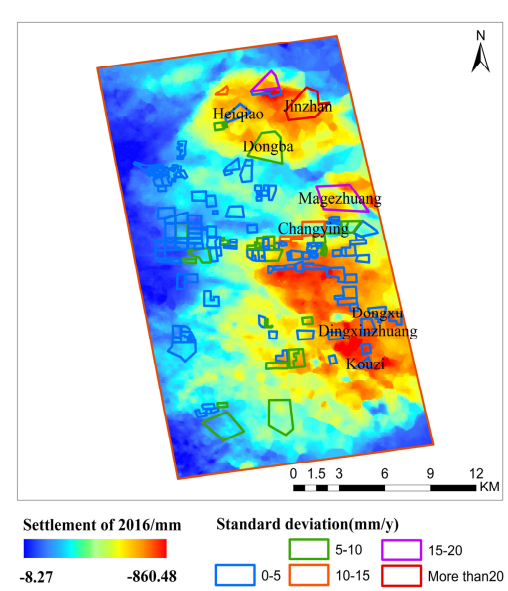

Figure 5. Distribution of building district with different standard deviation
Dividing the standard deviation of building blocks into five categories and counting each category number in six category of hydrogeological background, we discovered that there are 28 blocks with heterogeneous subsidence that the standard deviation is greater than 5. So, 28 uneven settlement blocks existing in this study area (Figure5).In this text, we use building numbers in each block to represent the size of the building density, and collet the building height and bottom area to calculate building volume of each single building. The Spearman's rank correlation coefficient is calculated between building volume and mean subsidence velocity of each single building. Through comparative analysis, we found that the size of the standard deviation is not synchronized with the building age and building density (Figure 6). Moreover, there are only two districts apparently shows that the settlement of high-rise buildings is relatively higher than low-rise building, accounting for $7 \%$ of the overall uneven settlement area(Figure 7).

And the reason of uneven settlement can be divided into three categories: 1) Affeted by groundwater, like Jinzhan, Dongba, Magezhuang, Heizhuanghu. The building density of these village is large than other districts. The uneven settlement of Jinzhan and Magezhuang is more serious than Dongba and Heizhuanghu and the subsidence rate gradually decreases to surroundings (Figure 6). We speculate that it is being affected by the changes of groundwater level of some underground well that excavated by villager. These underground well are not within the scope of normal monitoring.2) Affected by building load, such as Haitanggongshe and Tonghuijiayua. Its correlation coefficient between building volume and uneven settlement is greater than 0.5. 3) Other reasons, from interpolation results of land subsidence, the others uneven settlements mostly appears on the edge or the center of the sedimentation funnel. This indicates that regional uneven settlement is still subject to multiple factors, such as the changes of groundwater, the compressible thickness and fault zone. 

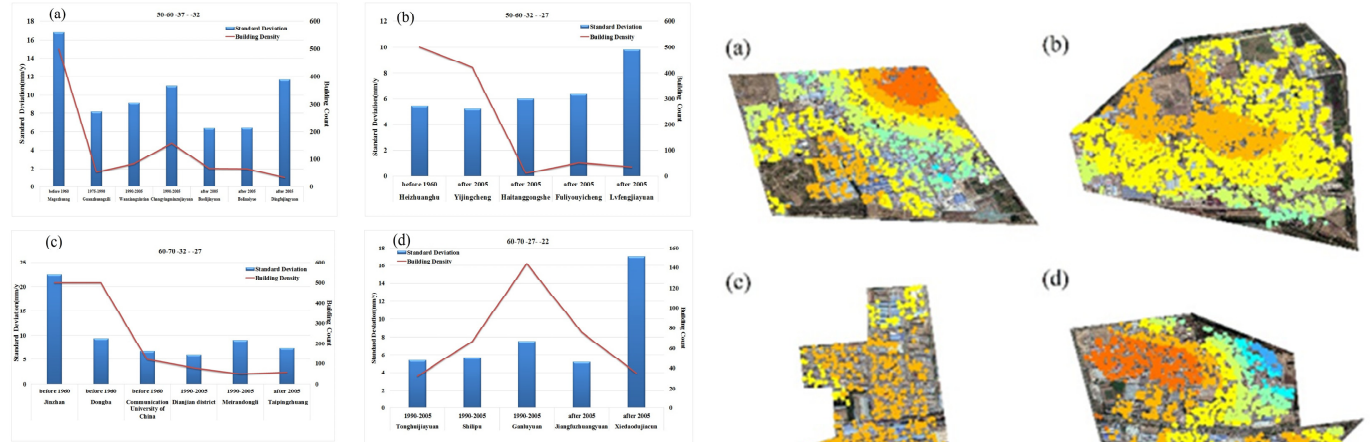

(c)

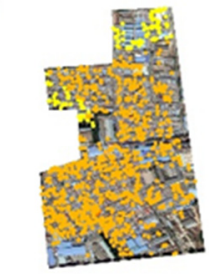

(d)

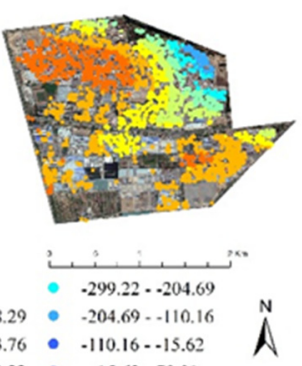

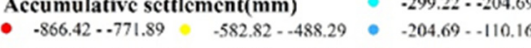

$-771.89-.677 .35 \div-488.29 \cdot-393.76 \bullet-110.16 \cdot-15.62$

$-677.35-582.82 \circ-393.76--299.22 \bullet-15.62-78.91$

Figure 6. (a) Trend map of standard deviation and building age, building density (b) villages that affected by groundwater
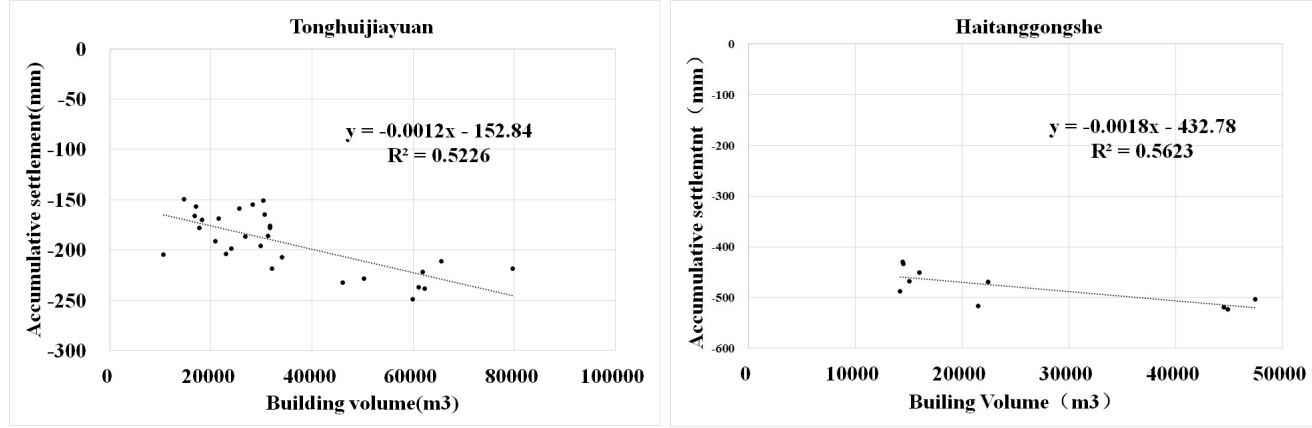

Figure 7. Trend map of standard deviation and building density

\section{CONCLUSIONS}

In this project, we select settlement funnel area as study area to analyze the relation between ground subsidence and building construction from two scale by using PS-InSAR technique, GIS and statistical analysis method. Subsidence rate in Beijing plain is range from $-141.3 \mathrm{~mm} / \mathrm{yr}$ to $+15.9 \mathrm{~mm} / \mathrm{yr}$, two obvious subsidence bowls distributed over the east of Chaoyang District and gradually connected into a trip. From regional scale, results reveal that the ground subsidence in settlement bowls is mostly controlled by groundwater and compressible layers, and not completely relevant with the age of the building construction. Some serious settlement areas appear in building-intensive blocks, the built age of these buildings relatively long and its subsidence rate gradually decreased from the center to the surrounding with settlement rate more than $100 \mathrm{~mm} / \mathrm{y}$. At local scale, 28 uneven settlement areas have been discovered, and the generation of uneven settlement blocks has closely related with urban construction in two districts, the others uneven settlements mostly appears on the edge or the center of the sedimentation funnel and still controlled by the changes of groundwater and compressible thickness.

\section{REFERENCES}

Abidin, H. Z., Andreas, H., Gumilar, I., Fukuda, Y., Pohan, Y. E. and Deguchi, T. (2011). Land subsidence of Jakarta (Indonesia) and its relation with urban development, Natural Hazards 59:1753-71.

Ferretti A., Prati C., and Rocca F. (2001). Permanent Scatterers in SAR Interferometry. IEEE TRANSACTIONS ON GEOSCIENCE AND REMOTE SENSING, 39(1). 
Yang et al., Study on the Relation between Urban Construction and Land Subsidence

Ferretti A., Prati C., and Rocca F. (2000). Nonlinear Subsidence Rate Estimation Using Permanent Scatterers in Differential SAR Interferometry. IEEE TRANSACTIONS ON GEOSCIENCE AND REMOTE SENSING, 38(5).

Chen, M., Tomás, R., Li, Z., Motagh, M., Li, T., Hu, L., Gong, H., Li, X., Yu, J. and Gong, X. (2016). Imaging Land Subsidence Induced by Groundwater Extraction in Beijing (China) Using Satellite Radar Interferometry, Remote Sensing 8:468.

Cui, Z., Tang, Y. and Yan, X. (2010). Centrifuge modeling of land subsidence caused by the high-rise building group in the soft soil area, Environmental Earth Sciences 59:1819-26.

Chen, B., Gong, H., Li, X., Lei, K., Gao, M., Zhou, C. and Ke, Y. (2015). Spatial-temporal evolution patterns of land subsidence with different situation of space utilization, Natural Hazards 77:1765-83.

Chen, B., Gong, H., Li, X., Lei, K., Zhu, L., Gao, M., \& Zhou, C. (2017). Characterization and causes of land subsidence in Beijing, China. International Journal of Remote Sensing, 38(3), 808-826.

Gao, M. L., Gong, H. L., Chen, B. B., Zhou, C. F., Liu, K. S. and Shi, M. (2015). Mapping and characterization of land subsidence in Beijing Plain caused by groundwater pumping using the Small Baseline Subset (SBAS) InSAR technique, Proceedings of the International Association of Hydrological Sciences 372:3479.

Gong, H. L., Zhang, Y. Q., Li, X. J., Lu , X. H., Chen, B. B. and Gu, Z. Q. (2009). Land subsidence research in Beijing based on Permanent Scatterers Radar Interferometry. Advances in Natural Science. 19(11), 12611266.

Hooper, A., Bekaert, D., Spaans, K. and Arıkan, M. (2012). Recent advances in SAR interferometry time series analysis for measuring crustal deformation, Tectonophysics 514-517:1-13.

Jie, Y. X., Gao, Y., Li, G. X., Sun, T. and Liu,Y. H. (2007). Discussion on influence depth of large-scale load in urban construction. Industrial Construction. 6(37), 57-62.

Lei, K. C., Chen. B. B., Jia. S. M., Wang, S. F. and Luo, Y. (2014). Primary Investigation of Formation and Genetic Mechanism of Land Subsidence Based on PS-InSAR Technology in Beijing. Spectroscopy and Spectral Analysis. 8, 2185-2189.

Lei, K. C., Luo, Y. Chen. B. B., Guo. G. X. and Zhou. Y. (2016). Distribution characteristics and influence factors of land subsidence in Beijing area, Geology in China. 43(6): 2216-2225.

Stramondo, S., Bozzano, F., Marra, F., Wegmuller, U., Cinti, F. R., Moro, M. and Saroli, M. (2008). Subsidence induced by urbanisation in the city of Rome detected by advanced InSAR technique and geotechnical investigations, Remote Sensing of Environment 112:3160-72.

Solari, L., Ciampalini, A., Raspini, F., Bianchini, S. and Moretti, S. (2016). PSInSAR Analysis in the Pisa Urban Area (Italy): A Case Study of Subsidence Related to Stratigraphical Factors and Urbanization, Remote Sensing 8:120.

Tosi, L., Da Lio, C., Strozzi, T. and Teatini, P. (2016). Combining L- and X-Band SAR Interferometry to Assess Ground Displacements in Heterogeneous Coastal Environments: The Po River Delta and Venice Lagoon, Italy, Remote Sensing 8:308.

Tang, Y. Q., Song, S. P., Chen, B., Wang, J, X. and Yang, P. (2010). Study on Land Subsidence Law of dense building group under different building volume ratio. Chinese Journal of Rock Mechanics and Engineering. 29(1), 3425-3431.

Yan, X. X., Gong, T. L., Zeng, Z. Q., Yu, J. Y., Shen, G. P. and Wang. T.J. (2002). Relationship between building density and land subsidence in Shanghai urban zone. Hydrogeology and Engineering Geology. 6(29), 21-25.

Zhu, L., Gong, H., Li, X., Li, Y., Su, X. and Guo, G. (2013). Comprehensive analysis and artificial intelligent simulation of land subsidence of Beijing, China, Chinese Geographical Science 23:237-48.

Zhou, C., Gong, H., Chen, B., Li, J., Gao, M., Zhu, F., Chen, W. and Liang, Y. (2017). InSAR Time-Series Analysis of Land Subsidence under Different Land Use Types in the Eastern Beijing Plain, China, Remote Sensing 9:380.

Zhu, L., Gong, H., Li, X., Wang, R., Chen, B., Dai, Z. and Teatini, P. (2015). Land subsidence due to groundwater withdrawal in the northern Beijing plain, China, Engineering Geology 193:243-55.

Liu, Z. Y. (2010). Technical specification implementation manual for engineering monitoring of foundation pit. China Construction Industry Press. 